\title{
Intestinal Enteroid Culture for Human Astroviruses
}

Irene A. Owusu ${ }^{1,2, \#}$, Carmen Mirabelli1, \# and Abimbola O. Kolawole ${ }^{3, *}$

\author{
${ }^{1}$ Department of Microbiology and Immunology, University of Michigan, Ann Arbor, Michigan, USA; ${ }^{2}$ West \\ African Center for Cell Biology of Infectious Pathogens, University of Ghana, Legon, Ghana; \\ ${ }^{3}$ Department of Biological Sciences, Wright State University, Dayton, Ohio, USA \\ *For correspondence: ola.kolawole@wright.edu \\ \#Contributed equally to this work
}

\begin{abstract}
[Abstract] Human astroviruses (HAstV) are non-enveloped, positive-sense single stranded RNA viruses that typically cause gastroenteritis in children, the elderly and among immunocompromised individuals. Some HAstV species have also been implicated in neurological diseases. It is important to study these viruses to understand the pathogenesis and develop therapeutics. Here we describe HAstV infection in epithelium-only human intestinal enteroids (HIE) isolated from biopsy-derived intestinal crypts. Although different HAstV clades have been propagated in transformed immortalized cell lines such as A549, Caco-2, HEK293T and Huh7.5, we chose HIE because they better mimic the human intestine and thus are more physiologically relevant. Additionally, HIE support the replication of all HAstV clades including clinical samples, thus making HIE a valuable potential universal model to study HAstV biology.
\end{abstract}

Keywords: Astrovirus, Enteric virus, Enteroid, Infection, VA, MLB, HAstV

[Background] Human astroviruses (HAstV) are enteric viruses that are highly prevalent, causing widespread infections ranging from diarrhea to encephalitis. Asymptomatic, systemic and extra-intestinal infections are common (Madeley and Cosgrove 1975; Bosch et al., 2014; Kolawole et al., 2019). Despite their medical importance, HAstV are some of the least characterized enteric viruses. Currently, three groups of human AstV are recognized: classic HAstV, and non-classic HAstV-MLB (Melbourne), and HAstV-VA/HMO (Virginia/Human-Mink-Ovine-like) with each group containing multiple strains. Several immortalized cell lines have been developed for successful propagation of multiple HAstV strains. Human colon carcinoma Caco-2 cells are commonly used to propagate all eight serotypes of classic HAstV. As for the non-classic HAstV, Caco-2 cells, human embryonic kidney HEK293T, adeno-carcinomic human lung epithelial A549, and primary astrocytes were only recently described to support VA1 propagation (Janowski et al., 2017 and 2019). In addition, A549 and human liver Huh7 were developed to propagate MLB1 and MLB2 (Vu et al., 2019). However, no single culture system supports the replication of all tested species. The lack of a robust, physiologically relevant viral propagation system for genetically diverse viruses from all clades has created a fundamental gap in our understanding about the biology of HAstV. For example, little or no information is available on the in vivo cell tropism, pathophysiology, and host responses to HAstV infection. 
Human intestinal enteroids (HIE) are nontransformed in vitro models that recapitulate many characteristics of the gastrointestinal tract. HIE are derived from stem cells isolated from human intestinal biopsy tissues or surgical resections. Thus, this system exhibits multiple advantages over traditional transformed intestinal cell lines (e.g., Caco-2 cells). These include the non-transformed status, the presence of multiple cell types, the specific regional characteristics and host genetics of the donor and the ability to differentiate from crypt-like into villus-like cell populations (Kolawole et al., 2019; Kolawole and Wobus, 2020). There are some drawbacks involved with using HIE. Examples include donor-to-donor variability, inability of HIE to completely mimic the cellularity of the intestine in vivo and the major investment needed for culture maintenance. However, HIE have been used to culture human rotavirus, norovirus and astrovirus by breaking apart the 3D spheres in which they are normally organized in culture (Figure 1, left) and seeding as 2D monolayer (Figure 1, right) (Kolawole and Wobus, 2020). Here, we describe our methods of HIE maintenance and AstV infection. Laboratory adapted samples of HAstV1, MLB1 and VA1 represented HAstV clades that were propagated in HIE. HAstV5-positive stool sample was also used to propagate clinical HAstV in HIE. All infections were performed in 2D monolayers. These protocols, with the required specific adjustments, should facilitate the study of HAstV and other enteric viruses.

\section{Materials and Reagents}

1. $1.7 \mathrm{ml}$ popsi-click centrifuge tubes (Denville, catalog number: C2170)

2. U-bottom 96-well plates (Falcon, catalog number: 353077 )

3. 48-well plates (Costar, catalog number: 3548 )

4. 24-well plates Nunclon delta surface (Thermo Scientific, catalog number: 142475)

5. 6-well plates (CytoOne, catalog number: CC7682)

6. P1000 pipette tips (Denville, catalog number: 1159M42)

7. P200 pipette tips (Denville, catalog number: 1159M40)

8. P20 pipette tips (Denville, catalog number: 1159M43)

9. $1 \mathrm{ml}$ disposable syringe (BD, catalog number: 309659$)$

10. $25 \mathrm{G} \times 5 / 8$ " PrecisionGlide needle (BD, catalog number: 305122 )

11. Cell strainer, $40 \mu \mathrm{m}$ nylon mesh (Fisherbrand, catalog number: 22363547)

12. $15 \mathrm{ml}$ conical tubes (Falcon, catalog number: 352096$)$

13. Sterile $500 \mathrm{ml}$ vacuum filtration systems $(0.22 \mu \mathrm{m}$, PES membrane; Corning, catalog number: 431097)

14. Sterile $250 \mathrm{ml}$ vacuum filtration systems $(0.22 \mu \mathrm{m}$, PES membrane; Corning, catalog number: 431096)

15. Sterile $50 \mathrm{ml}$ vacuum filtration systems $(0.22 \mu \mathrm{m}$; Millipore, catalog number: SCGP00525)

16. Matrigel matrix (Corning, catalog number: 354234 )

17. Fetal bovine serum (FBS; HyClone, catalog number: SH30396.03)

18. LWRN cells (ATCC, catalog number: CRL-3276) 
19. Advanced DMEM/F-12 (Invitrogen, catalog number: 12634-028)

20. N-2 media supplement (Invitrogen, catalog number: 17502-048)

21. Phosphate buffered saline (PBS ${ }^{-1-}$; Gibco, catalog number: 10010-023)

22. Dulbecco's phosphate buffered saline with calcium and magnesium $\left(\mathrm{PBS}^{+/+} ;\right.$Gibco, catalog number: 14040-133)

23. HEPES (1 M; Invitrogen, catalog number: 15630-080)

24. 5000 units/ml penicillin/streptomycin (Invitrogen, catalog number: 15070-063)

25. Geneticin, G418 (Gibco, catalog number: 10131-035)

26. Hygromycin B (Invitrogen, catalog number: 10687010)

27. Puromycin (Sigma-Aldrich, catalog number: P8833)

28. GlutaMax (Invitrogen, catalog number: 17504-044)

29. B-27 supplement minus vitamin A (Invitrogen, catalog number: 17504-044)

30. N-Acetyl-L-cysteine (Sigma-Aldrich, catalog number: A9165-5G)

31. Mouse EGF (Invitrogen, catalog number: PMG8043)

32. SB202190 (Sigma-Aldrich, catalog number: S7067)

33. A83-01 (Tocris, catalog number: 2939)

34. Nicotinamide (Sigma-Aldrich, catalog number: N0636)

35. Leu15-Gastrin I (Sigma-Aldrich, catalog number: G9145)

36. Y-27632 (Sigma-Aldrich, catalog number: Y0503)

37. Human collagen IV (Sigma, catalog number: C5533)

38. Porcine trypsin (Sigma-Aldrich, catalog number: T-0303)

39. $0.05 \%$ Trypsin-EDTA (Gibco, catalog number: 25300-054)

40. Recovery cell culture freezing medium (Gibco, catalog number: 12648-010)

41. Glacial acetic acid (Thermo Scientific, catalog number: A38-211)

42. UltraPure distilled water (Invitrogen, catalog number: 10977-015)

43. Dimethyl sulfoxide (DMSO; Sigma, catalog number: D2650)

44. Accumax (STEMCELL technologies, catalog number: 07921)

45. LIVE/DEAD fixable aqua dead cell stain kit (Thermo Fisher Scientific, catalog number: L34957)

46. Fixation/Permeabilization concentrate (eBioscience, catalog number: 00-5123-43)

47. Biotin-conjugated primary dsRNA (J2; Scicons, catalog number: 10010200)

48. Rabbit anti-ZO1 primary antibody (Thermo Fisher Scientific, catalog number: 61-7300)

49. Mouse anti-VA1 polyclonal serum (primary antibody; made in our lab)

50. Secondary anti-rabbit AlexaFluor 594 (Thermo Fisher Scientific, catalog number: A32740)

51. Secondary anti-mouse AlexaFluor 647(Thermo Fisher Scientific, catalog number: A32728)

52. Ulex europeus agglutinin 1 (UEA-1) lectin conjugated with FITC (Thermo Fisher Scientific, catalog number: L32476)

53. 4',6-Diamidino-2-phenylindole (DAPI; Sigma-Aldrich, catalog number: D9542)

54. ProLong Gold antifade reagent (Thermo Fisher Scientific, catalog number: P36930)

55. Transwell permeable support (Costar, catalog number: 3413) 
56. Stock solutions (see Recipes)

$500 \mathrm{mM}$ N-acetyl cysteine

$50 \mu \mathrm{g} / \mathrm{ml}$ Mouse EGF

$500 \mathrm{mM}$ A-83-01

$10 \mathrm{mM}$ SB202190

$1 \mathrm{M}$ Nicotinamide

$10 \mu \mathrm{M}$ Leu15-Gastrin

$10 \mathrm{mM}$ Y-27632

57. Media (see Recipes)

Advanced DMEM-20

LWRN conditioned medium

Noggin conditioned medium

LWRN'- medium (1\%)

$\mathrm{LWRN}^{+}$(with growth factors)

Differentiation medium

\section{Equipment}

1. $37^{\circ} \mathrm{C}$ incubator (Thermo Scientific Heracell $150 \mathrm{i} \mathrm{CO}_{2}$ Incubator)

2. $37^{\circ} \mathrm{C}$ water bath (Thermo Electron Corporation)

3. $-80^{\circ} \mathrm{C}$ freezer

4. Benchtop Centrifuge (Sorval legend RT)

5. Hemocytometer (Reichert)

6. P1000 pipette (Eppendorf Research)

7. P200 pipette (Eppendorf Research)

8. P20 pipette (Eppendorf Research)

9. Vacuum aspirator

10. Biosafety hood (SterilGARD ${ }^{\circledR}$ III Advance)

11. Light microscope (Fisher Scientific)

12. Cell counter

\section{Procedure}

A. Reviving enteroids from liquid nitrogen storage

1. Thaw Matrigel aliquot overnight at $4{ }^{\circ} \mathrm{C}$.

2. Add $10 \mathrm{ml}$ of LWRN- into a $15 \mathrm{ml}$ conical tube and leave on ice.

3. Transfer frozen vial containing enteroids from liquid nitrogen under running tap water at room temperature (a frozen vial usually contains about 150-200 enteroids).

4. Transfer content into the $15 \mathrm{ml}$ conical tube containing LWRN- 
5. Spin down cells in a refrigerated centrifuge at $80 \times g$ for 5 min at $4{ }^{\circ} \mathrm{C}$.

6. Aspirate medium and suspend pellet in Matrigel (calculate the required volume of Matrigel based on the total number of wells that will be seeded with enteroids).

7. Plate enteroids in $10 \mu \mathrm{l}$ Matrigel drops in a 24-well plate, four drops per well (seed 3 wells of 4 drops from one cryovial of $500 \mu \mathrm{l})$.

8. Allow the Matrigel to solidify in a $37^{\circ} \mathrm{C}$ incubator for $10 \mathrm{~min}$.

9. Add $1 \mathrm{ml}$ of $\mathrm{LWRN}^{+}$medium to each well containing enteroids suspended in Matrigel.

10. Incubate at $37^{\circ} \mathrm{C}, 5 \% \mathrm{CO}_{2}$.

11. Replace medium every two days until enteroids are ready to be passaged after 6 to 7 days (Figure 1, left).

B. Passaging and maintaining enteroids (procedure for 1-10 wells)

1. Preparation: Keep pipette tips in refrigerator for about $30 \mathrm{~min}$ before start. Warm up the plates.

2. Carefully aspirate medium from wells without disturbing Matrigel.

3. Add $500 \mu \mathrm{l}$ of cold LWRN' to each well and mechanically break up Matrigel by pipetting up and down 3-5 times with a P1000 pipette. Optimize the level of pipetting for each enteroid line.

4. Using a $1 \mathrm{ml}$ syringe with a $25 \mathrm{G} \times 5 / 8$ " needle, push broken Matrigel in and out 3-4 times per well, transfer the contents of the well into a $15 \mathrm{ml}$ conical tube (cells will not be damaged by the needle; if there are multiple wells of the same enteroid line, combine up to 10 wells in the same tube).

5. Add another $500 \mu \mathrm{l}$ of cold LWRN $\mathrm{N}^{-}$to each well and transfer the content into the $15 \mathrm{ml}$ tube with the syringe. Add at least $5 \mathrm{ml}$ total volume to $15 \mathrm{ml}$ tube.

6. Spin down cells in a refrigerated centrifuge at $80 \times g$ at $4{ }^{\circ} \mathrm{C}$ for $5 \mathrm{~min}$.

7. Carefully remove and discard supernatant and keep enteroid pellet on ice.

8. Suspend enteroid pellet in Matrigel on ice. Matrigel must be kept cold to avoid solidification.

9. Using cold P20 pipette tips, plate enteroids in $10 \mu \mathrm{l}$ Matrigel drops in a 24-well plate, four drops per well.

10. Transfer plate into a $37^{\circ} \mathrm{C}$ incubator and allow the Matrigel to set for $10 \mathrm{~min}$.

11. Add $500 \mu \mathrm{l}$ of room temperature $\mathrm{LWRN}^{+}$to each well and incubate in a $37{ }^{\circ} \mathrm{C}, 5 \% \mathrm{CO}_{2}$ incubator

12. Replace medium every two days until enteroids are ready to be passaged (usually after 6 or 7 days) (Figure 1, left). 

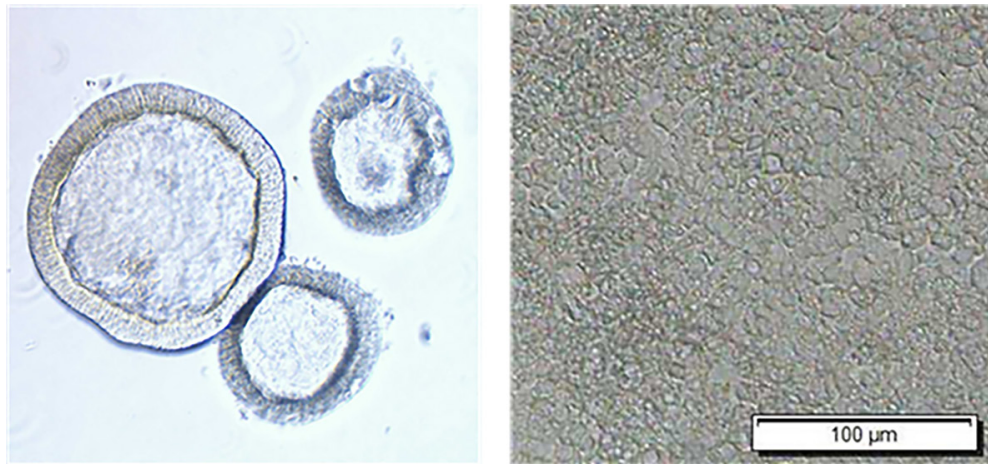

Figure 1. 3D and 2D human intestinal enteroids. Fetal ileum line were kept in $\mathrm{LWRN}^{+}$culture media for 4 days (left; 3D) or seeded in 48-well plate and kept in differentiation media for 6 days (right; 2D)

C. Making and maintaining 2D enteroid monolayers on Transwells and 48-well plates

1. Prepare a collagen IV stock solution ( $1 \mathrm{mg} / \mathrm{ml}$ in $100 \mathrm{mM}$ glacial acetic acid).

a. Prepare $100 \mathrm{mM}$ acetic acid by adding $60 \mu \mathrm{l}$ of $100 \%$ acetic acid to $10 \mathrm{ml}$ sterile water.

b. Suspend $1 \mathrm{mg}$ of collagen IV in $1 \mathrm{ml}$ of $100 \mathrm{mM}$ acetic acid to make collagen IV stock solution and vortex to mix.

C. Aliquot in $500 \mu \mathrm{l}$ and store at $-20^{\circ} \mathrm{C}$.

2. Prepare a 1:30 dilution of collagen IV stock solution in cold sterile water.

3. Add $100 \mu \mathrm{l}$ of the cold diluted collagen IV solution to each Transwell or $200 \mu \mathrm{l}$ to each well in the 48 -well plate and incubate at $37^{\circ} \mathrm{C}$ for $2 \mathrm{~h}$ for the collagen to solidify.

4. Take off the culture medium from well, and break enteroids apart by adding $500 \mu \mathrm{l} /$ well of cold $0.5 \mathrm{mM}$ EDTA wash solution (made by diluting $10 \mu \mathrm{l}$ of $500 \mathrm{mM}$ EDTA to $10 \mathrm{ml} \mathrm{PBS}^{-1-}$ ) and pipetting up and down 5 times.

5. Transfer the enteroid solution into a sterile $15 \mathrm{ml}$ tube.

6. Add another $500 \mu \mathrm{l} /$ well of cold $0.5 \mathrm{mM}$ EDTA wash solution to each well and transfer into the $15 \mathrm{ml}$ tube. Add at least $5 \mathrm{ml}$ total volume to $15 \mathrm{ml}$ tube.

7. Spin at $300 \times g$ for $5 \mathrm{~min}$ at $4{ }^{\circ} \mathrm{C}$ to pellet the cells (if pellet is not compact, then re-spin).

8. Carefully remove and discard supernatant using a $10 \mathrm{ml}$ pipette. A small amount of residual liquid is okay.

9. Re-suspend pellet in $500 \mu \mathrm{l} 0.05 \%$ trypsin by pipetting up and down with $\mathrm{P} 1000$ (500 $\mu \mathrm{l}$ trypsin for 1-5 wells combined or $1 \mathrm{ml}$ trypsin for 6-10 wells of enteroids).

10. Incubate at $37^{\circ} \mathrm{C}$ for $4-6$ min (optimize the incubation time for each enteroid line).

11. Inactivate trypsin by adding $1 \mathrm{ml}$ of LWRN- medium containing $10 \%$ FBS.

12. Dissociate the enteroids by vigorously pipetting up and down $40-50$ times using P1000 pipette (optimize the specific number of times for each enteroid line; avoid forming bubbles by pipetting against the wall of the tube).

13. Put a $40 \mu \mathrm{m}$ cell strainer over a $50 \mathrm{ml}$ conical tube.

14. Pre-wet the strainer by passing $1 \mathrm{ml}^{\text {of }} \mathrm{LWRN}^{-}$medium supplemented with $10 \%$ FBS. 
15. Add the cells onto the strainer and allow the cells to flow through by gravity.

16. Rinse the strainer with additional 1 ml LWRN'.

17. Pellet the cell suspension by centrifuging at $400 \times g$ at $4{ }^{\circ} \mathrm{C}$ for $5 \mathrm{~min}$.

18. Remove and discard supernatant with a $10 \mathrm{ml}$ pipette and carefully remove the remaining liquid with a P200 pipette without disturbing the pellet.

19. Suspend the cell pellet in $100-1,000 \mu \mathrm{L} \mathrm{LWRN}^{+}$medium containing $10 \mu \mathrm{M} \mathrm{Y}-27632$. Take a small aliquot of the cells and count with hemocytometer.

20. Remove the collagen coating solution from the Transwell or plate.

21. Plate by adding $1 \times 10^{5}$ cells dropwise into the middle of the collagen-coated Transwell or plate (100 $\mu \mathrm{l}$ per Transwell or $200 \mu \mathrm{l}$ per 48-well). The cells will spread out and coat the well so do not rotate or swirl the seeded plate.

22. Add $600 \mu \mathrm{l}$ of $\mathrm{LWRN}^{+}$medium containing $10 \mu \mathrm{M} \mathrm{Y}-27632$ in the lower compartment of the Transwell.

23. The next day, remove the $L W R N^{+}$medium containing $10 \mu \mathrm{M} \mathrm{Y}-27632$ and replace with $L W R N^{+}$ medium only.

24. Replace medium every two days until enteroids are ready to be infected (usually when cells are about $80-90 \%$ confluent).

25. If there was a need to infect differentiated cells, add differentiation medium to the upper $(100 \mu \mathrm{l})$ and lower $(600 \mu \mathrm{l})$ compartments of Transwells or $200 \mu \mathrm{l}$ to 48 -well plate to differentiate $2 \mathrm{D}$ enteroids when the wells are $80-90 \%$ confluent.

26. Replace differentiation medium every two days until enteroids are ready to be infected (usually after 3-7 days) (Figure 1, right).

D. Human astrovirus infection of enteroid 2D monolayer

1. Thaw HAstV1, MLB1, VA1 and mock cell lysates plus HAstV5-positive stool filtrate at room temperature (expand HAstV1 and VA1 in Caco-2 cells; expand MLB1 in Huh7.5 cells; freeze and lyse infected cells to yield virus stock; filter HAstV5-psitive stool sample collected in AMES buffer through $0.22 \mu \mathrm{m}$; titer virus stock by RT-qPCR to determine the genome copies).

2. Dilute MLB1 and VA1 as $10^{5}$ genome copies per $100 \mu$ l of LWRN- medium only while HAstV1 and HAstV5 diluent should contain $5 \mu \mathrm{g} / \mathrm{ml}$ porcine trypsin.

3. Incubate HAstV1 and HAstV5 in the trypsin solution above for $1 \mathrm{~h}$ at $37^{\circ} \mathrm{C}, 5 \% \mathrm{CO}_{2}$.

4. Rinse the enteroid monolayer once with cold LWRN'- medium.

5. Remove media and gently add $100 \mu$ liluted virus.

6. Incubate the infected cells for $1 \mathrm{~h}$ at $37^{\circ} \mathrm{C}, 5 \% \mathrm{CO}_{2}$.

7. Remove the inoculum and gently wash the monolayer once with LWRN- medium.

8. Store a plate containing few wells with infected $\mathrm{HIE}$ at $-80^{\circ} \mathrm{C}$ as $0 \mathrm{~h}$ to measure the initial inoculum.

9. Add $200 \mu \mathrm{l}\left(100 \mu \mathrm{l}\right.$ in Transwell insert) $\mathrm{LWRN}^{+}$or differentiation medium to the remaining wells $\left( \pm 2 \mu \mathrm{g} / \mathrm{ml}\right.$ porcine trypsin) and incubate at $37^{\circ} \mathrm{C}, 5 \% \mathrm{CO}_{2}$ till harvest. 
10. Collect supernatant and cells separately during harvest.

11. Store at $-80^{\circ} \mathrm{C}$ during harvest until analysis.

E. Immunofluorescent staining of astrovirus-infected 2D enteroid monolayers on Transwells

1. Remove media from wells in both apical and basal compartment.

2. Wash once with warm $100 \mu \mathrm{DPBS}^{+/+}$.

3. Fix cells with $100 \%$ methanol for $15 \mathrm{~min}$ at $-20^{\circ} \mathrm{C}$ in both apical and basal compartment.

4. Aspirate fixative and wash twice with $100 / 500 \mu \mathrm{l}$ (apical/basal) DPBS ${ }^{+/+}$.

5. Block with $\mathrm{DPBS}^{+/+}$containing $0.1 \%$ Triton-X100 and $3 \% \mathrm{BSA}$ for $1 \mathrm{~h}$.

6. Add $100 \mu \mathrm{LPBS}^{+/+}$containing $0.1 \%$ Triton-X100, 3\% BSA and the appropriate primary antibodies overnight at $4{ }^{\circ} \mathrm{C}$ on the apical side (example of primary antibodies include VA1 for virus, ZO1 for tight junction, UEA-1 for multiple intestinal cells, DAPI for nucleus). Keep the blocking buffer in the basal compartment.

7. Aspirate antibody and wash twice each with $100 \mu \mathrm{LPBS}^{+/+}$.

8. Add $100 \mu \mathrm{LPBS} \mathrm{DP}^{+/+}$containing $0.1 \%$ Triton-X100, $3 \% \mathrm{BSA}$ and the appropriate secondary antibodies for $1 \mathrm{~h}$ at RT and away from light.

9. Wash thrice with $\mathrm{DPBS}^{+/+}$.

10. Add $100 \mu \mathrm{LPBS}^{+/+}$containing appropriate amount of DAPI for $5 \mathrm{~min}$ at RT.

11. Wash thrice with $\mathrm{DPBS}^{+/+}$.

12. Cut out membrane from the Transwell with care and place on microscope slide with apical side face up.

13. Place a drop of Prolong gold (without DAPI) on the membrane and place a coverslip to cover the cells.

14. Drain excess prolong and seal with nail polisher.

15. Allow the cells to dry at RT overnight and place at $4{ }^{\circ} \mathrm{C}$ before imaging with the confocal microscope (Figure 2).
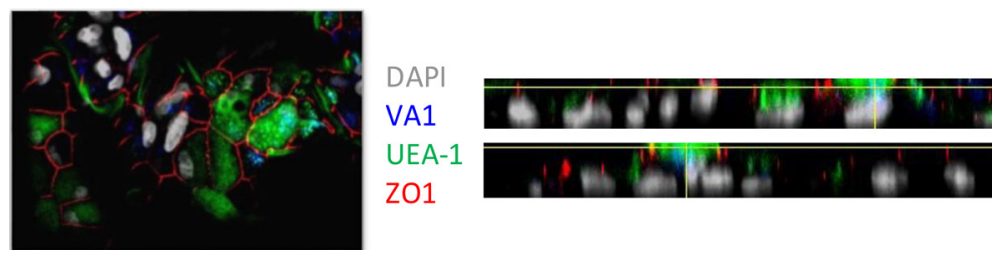

Figure 2. Differentiated fetal ileum 2D enteroids were infected with HAstV-VA1 for $\mathbf{5}$ days prior to immunofluorescence. Cells were stained with FITC-conjugated UEA-1 (green; multiple intestinal cells), ZO1 (red; tight junction), DAPI (grey; nucleus) and VA1 (blue; virus) antibodies. Image was acquired with a confocal microscope. Z-stack: maximum intensity projection (left) and orthogonal view (right).

F. Flow cytometry analysis of astrovirus-infected $2 \mathrm{D}$ enteroid monolayers

1. Aspirate media from wells. 
2. Add $100 \mu \mathrm{l}$ Accumax and incubate at $37^{\circ} \mathrm{C}$ for $5 \mathrm{~min}$.

3. Collect cells in $1.7 \mathrm{ml}$ centrifuge tube on ice and repeat Step F2 if the cells are not detached.

4. Add $500 \mu \mathrm{LWRN}$ - supplemented with $2 \mathrm{mM}$ of EDTA and pipette up and down to break big cells aggregates.

5. Centrifuge cells at $400 \times g$ for 5 min at $4{ }^{\circ} \mathrm{C}$.

6. Re-suspend the pellet in $100 \mu \mathrm{LWRN}-\mathrm{LDTA}$ and transfer into a round bottom 96-well plate. Pellet the cells by centrifugation at $400 \times g$ for 5 min at $4{ }^{\circ} \mathrm{C}$.

7. Add $100 \mu \mathrm{l}$ of LWRN-EDTA containing live/dead fixable stain for $15 \mathrm{~min}$ at RT.

8. Spin cells at $400 \times g$ for $5 \mathrm{~min}$ at $4^{\circ} \mathrm{C}$ and wash with LWRN-EDTA twice.

9. Add $100 \mu \mathrm{l}$ LWRN-EDTA containing $0.5 \%$ BSA and selected surface markers for 20 min at RT in the dark (example; UEA-1 for multiple intestinal cell types).

10. Wash twice with $100 \mu \mathrm{l}$ LWRN-EDTA each.

11. Fix cells with fixation/permeabilization buffer for 20 min at room RT.

12. Wash twice each with $100 \mu$ permeabilization buffer and leave the cells for at least $3 \mathrm{~h}$ at $4{ }^{\circ} \mathrm{C}$.

13. Add primary antibody (anti-dsRNA as virus marker in permeabilization buffer) for 20 min at RT.

14. Wash twice each with $100 \mu$ l permeabilization buffer.

15. Re-suspend in $100 \mu$ permeabilization buffer containing appropriately fluorophore labeled secondary antibodies for 20 min at RT.

16. Wash twice each with $100 \mu$ permeabilization buffer.

17. Suspend in $500 \mu$ permeabilization buffer. Keep in tubes for flow cytometer analysis (Figure 3).

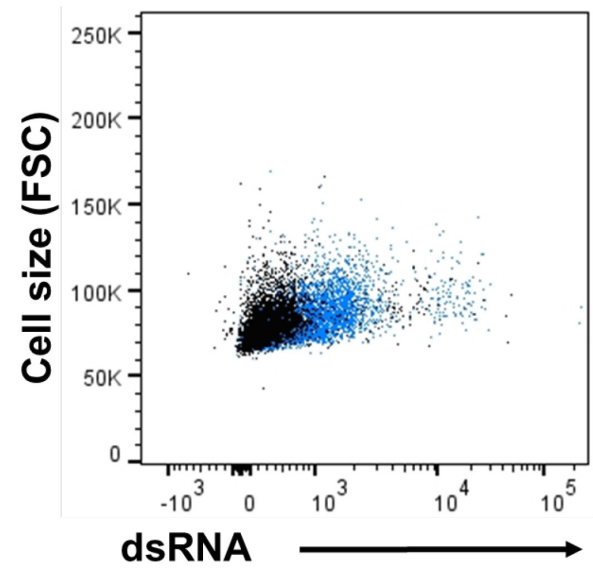

Figure 3. Flow cytometry data of infected HIE. Single cell suspensions of HAstV-VA1-infected fetal ileum enteroids were prepared at $3 \mathrm{dpi}$. Infected cells were stained with dsRNA (virus replication intermediate) to detect intracellular virus. Representative flow graph of total cell population that was alive (mock, black; VA1 infected, blue). 


\section{$\underline{\text { Recipes }}$}

\section{Working Environment}

1. All preparations and procedures must be done under the sterile conditions of a biosafety hood.

2. Appropriate personal protective equipment must be worn.

3. Transfer all waste into a biohazard bag in the biosafety hood. Spray the bag with $10 \%$ bleach and transfer into a secondary biohazard bag before disposal. Spray the inside of the biosafety hood and all equipment that are used during experiments with $10 \%$ bleach. Wipe clean with paper towel. Spray with sterile water to remove residual bleach and wipe off. Spray with $90 \%$ ethanol and allow it to dry. Close the sash and turn on the UV for 30 min to completely inactive virus.

\section{Stock solutions}

\section{Reagent}

$\mathrm{N}$-acetyl cysteine

Mouse EGF

A-83-01

SB202190

Nicotinamide

Leu15-Gastrin

Y-27632

Solvent
$\mathrm{ddH}_{2} \mathrm{O}$
PBS

DMSO

DMSO

$\mathrm{ddH}_{2} \mathrm{O}$

PBS

$\mathrm{ddH}_{2} \mathrm{O}$

$\begin{array}{ll}\text { Stock concentration } & \text { Working concentration } \\ 500 \mathrm{mM} & 1 \mathrm{mM} \\ 50 \mu \mathrm{g} / \mathrm{ml} & 50 \mathrm{ng} / \mathrm{ml} \\ 500 \mathrm{mM} & 500 \mu \mathrm{M} \\ 10 \mathrm{mM} & 10 \mu \mathrm{M} \\ 1 \mathrm{M} & 1 \mathrm{mM} \\ 10 \mu \mathrm{M} & 10 \mathrm{nM} \\ 10 \mathrm{mM} & 10 \mu \mathrm{M}\end{array}$

\section{Media}

1. Advanced DMEM-20

This medium is used to generate conditioned media.

a. Add $125 \mathrm{ml}$ FBS to $500 \mathrm{ml}$ Advanced DMEM/F-12

b. Add $6.25 \mathrm{ml} 5,000$ units $/ \mathrm{ml}$ pen/strep (antibiotics)

c. Add $6.25 \mathrm{ml}$ GlutaMax

d. Mix by gently inverting thrice

e. Label container appropriately and store medium at $4{ }^{\circ} \mathrm{C}$. The medium can remain at $4{ }^{\circ} \mathrm{C}$ for 1 month

2. LWRN conditioned medium

LWRN cells are used to generate conditioned medium that contains L-Wnt3a, R-spondin 1 and noggin, which are used to properly maintain human intestinal enteroids (HIE). The cells are a kind donation from Dr. Jason Spence (University of Michigan, also available at ATCC). LWRN conditioned medium can also be directly purchased from the translational tissue modeling laboratory, University of Michigan Medical School, Ann Arbor, Michigan, USA.

a. Prepare dual selection medium ( $0.5 \mathrm{mg} / \mathrm{ml}$ both $\mathrm{G} 418$ and hygromycin in DMEM-20)

b. Thaw LWRN cells stored in liquid nitrogen under running tap water at room temperature 
c. Transfer content into a $15 \mathrm{ml}$ tube containing $9 \mathrm{ml}$ Advanced DMEM/F12 and centrifuge at $100 \times g$ for 5 min at $4{ }^{\circ} \mathrm{C}$ to pellet the cells

d. Suspend the cells in $1 \mathrm{ml}$ dual selection medium and transfer into a $15 \mathrm{~cm}$ tissue culture treated dish containing $19 \mathrm{ml}$ dual selection medium

e. Incubate at $37^{\circ} \mathrm{C}, 5 \% \mathrm{CO}_{2}$ until about $90 \%$ confluent (usually $\sim 5$ days)

f. Split the cells at 1:10 into new tissue culture treated dishes with $20 \mathrm{ml}$ Advanced DMEM-20 and incubate

g. At $80 \%$ cell confluence, harvest LWRN supernatant by pouring off medium from cells, replace with $20 \mathrm{ml}$ fresh Advanced DMEM-20 and incubate. Consider this harvest as day 0 .

h. Filter-sterilize the harvested LWRN supernatant with $0.22 \mu \mathrm{m}$ filtration system. Make $50 \mathrm{ml}$ aliquots in conical tubes and store at $-80^{\circ} \mathrm{C}$

i. Harvest supernatant and replace medium every 2 days over a maximum of 12 days (about 7 harvests). Repeat Step $\mathrm{h}$ after each harvest

3. Noggin conditioned medium

Noggin is an important component of the differentiation medium required for HIE differentiation. HEK293 cells that express Fc-tagged noggin were kindly provided by Dr. Mary Estes (Baylor College, Texas, USA).

a. Prepare single selection medium ( $10 \mu \mathrm{g} / \mathrm{ml}$ puromycin in Advanced DMEM-20)

b. Thaw HEK293 cells expressing Fc-tagged Noggin stored in liquid nitrogen under running tap water at room temperature

c. Transfer content into a $15 \mathrm{ml}$ tube containing $9 \mathrm{ml}$ Advanced DMEM/F12 and centrifuge at $100 \times g$ for 5 min at $4{ }^{\circ} \mathrm{C}$ to pellet the cells

d. Suspend the cells in $1 \mathrm{ml}$ single selection medium and transfer into a $10 \mathrm{~cm}$ tissue culture treated dish containing $9 \mathrm{ml}$ Advanced DMEM-20

e. Incubate at $37^{\circ} \mathrm{C}, 5 \% \mathrm{CO}_{2}$ until the plate become confluent

f. Split cells at 1:10 into new $10 \mathrm{ml}$ tissue culture treated dishes with $15 \mathrm{ml}$ Advanced DMEM-20 and incubate

g. At $80 \%$ cell confluence, remove and discard old medium off cells and replace with fresh Advanced DMEM-20.

h. Harvest supernatant one-time after 5 days, filter sterilize with a $0.22 \mu \mathrm{m}$ filtration system and store at $-80^{\circ} \mathrm{C}$

4. LWRN- medium (1\%)

This is the basal medium that is used to wash enteroids.

a. To $500 \mathrm{ml}$ Advanced DMEM/F-12, add the following

$5 \mathrm{ml}$ GlutaMax

$5 \mathrm{ml}$ HEPES

$5 \mathrm{ml} 5000$ units $/ \mathrm{ml}$ pen/strep

b. Mix by gently inverting thrice 
C. Label container appropriately and store medium at $4{ }^{\circ} \mathrm{C}$. The medium stored at $4{ }^{\circ} \mathrm{C}$ is good for up to 4 weeks

5. LWRN $^{+}$(with growth factors)

This is the complete medium with growth factors that is used to maintain enteroids.

a. To prepare a $100 \mathrm{ml}$ medium, add the following from the stock solutions:

$50 \mathrm{ml}$ LWRN conditioned medium

$2 \mathrm{ml} \mathrm{B} 27$ supplement

$1 \mathrm{ml} \mathrm{N} 2$ supplement

$200 \mu \mathrm{l}$ N-acetylcysteine

$100 \mu \mathrm{EGF}$

$100 \mu \mathrm{l}$ Leu15-Gastrin

$100 \mu \mathrm{A}$ A83-01

$100 \mu \mathrm{l} \mathrm{SB202190}$

$1 \mathrm{ml}$ Nicotinamide

$45.6 \mathrm{ml} \mathrm{LWRN}^{-}$

b. Mix by gently inverting

c. Filter-sterilize with a $0.22 \mu \mathrm{m}$ filtration system

d. Label container appropriately and store medium at $4{ }^{\circ} \mathrm{C}$. The medium stored at $4{ }^{\circ} \mathrm{C}$ is good for up to 2 weeks

6. Differentiation medium

This is used to differentiate $2 \mathrm{D}$ monolayer enteroids from crypt-like into villus-like cell populations in culture.

a. To prepare a $50 \mathrm{ml}$ medium, add the following from the stock solutions:

$2.5 \mathrm{ml}$ noggin conditioned medium

$1 \mathrm{ml} \mathrm{B27}$ supplement

$500 \mu \mathrm{l} \mathrm{N} 2$ supplement

$100 \mu \mathrm{l}$-acetylcysteine

$50 \mu \mathrm{l} \mathrm{EGF}$

$50 \mu$ Leu15-Gastrin

$50 \mu \mathrm{l}$ A83-01

$45.75 \mathrm{ml} \mathrm{LWRN}^{-}$

b. Mix by gently inverting

c. Filter-sterilize with a $50 \mathrm{ml} 0.22 \mu \mathrm{m}$ filtration system

d. Label container appropriately and store medium at $4{ }^{\circ} \mathrm{C}$. The medium stored at $4{ }^{\circ} \mathrm{C}$ is good for up to 2 weeks

\section{Acknowledgments}

This protocol was adapted from the publication of Kolawole et al. (2019). The Michigan Medicine 
translational tissue modeling laboratory provided intestinal enteroids. Funding for the research was supported by NIH R21-Al141835.

\section{Competing interests}

The authors declare no competing interests.

\section{$\underline{\text { References }}$}

1. Bosch, A., Pinto, R. M. and Guix, S. (2014). Human astroviruses. Clin Microbiol Rev 27(4): 1048-1074.

2. Janowski, A. B., Bauer, I. K., Holtz, L. R. and Wang, D. (2017). Propagation of Astrovirus VA1, a Neurotropic Human Astrovirus, in cell culture. J Virol 91(19).

3. Janowski, A. B., Klein, R. S. and Wang, D. (2019). Differential in vitro infection of neural cells by Astroviruses. mBio 10(4).

4. Kolawole, A. O., Mirabelli, C., Hill, D. R., Svoboda, S. A., Janowski, A. B., Passalacqua, K. D., Rodriguez, B. N., Dame, M. K., Freiden, P., Berger, R. P., Vu, D. L., Hosmillo, M., O'Riordan, M. X. D., Schultz-Cherry, S., Guix, S., Spence, J. R., Wang, D. and Wobus, C. E. (2019). Astrovirus replication in human intestinal enteroids reveals multi-cellular tropism and an intricate host innate immune landscape. PLoS Pathog 15(10): e1008057.

5. Kolawole, A. O. and Wobus, C. E. (2020). Gastrointestinal organoid technology advances studies of enteric virus biology. PLoS Pathog 16(1): e1008212.

6. Madeley, C. R. and Cosgrove, B. P. (1975). Letter: Viruses in infantile gastroenteritis. Lancet 2(7925): 124.

7. Vu, D. L., Bosch, A., Pinto, R. M., Ribes, E. and Guix, S. (2019). Human astrovirus MLB replication in vitro: persistence in extraintestinal cell lines. $J$ Virol 93(13). 